\title{
Effectiveness of ecotechnologies
} for recovery of nitrogen and phosphorus from anaerobic digestate and effectiveness of the recovery products as fertilisers: a systematic review protocol

\author{
Biljana Macura ${ }^{*} \mathbb{D}$, Solveig L. Johannesdottir ${ }^{2}$, Mikołaj Piniewski ${ }^{3}$, Neal R. Haddaway ${ }^{1,4}$
} and Elisabeth Kvarnström ${ }^{5}$

\begin{abstract}
Background: The regular addition of plant-available nutrients such as nitrogen and phosphorus, either as manufactured fertilisers or animal manure, to agricultural soils is needed for global food security. Increased recycling of nutrients back to agriculture from organic waste streams is necessary for increased rural-urban sustainability. Anaerobic digestion of sewage sludge and agricultural wastes is widely applied to stabilize the substrate and also capture its energetic value via biogas production. The liquid phase of anaerobic digestate is a concentrated source of nutrients to which nutrient recovery technologies can be applied. Two such promising technologies that could increase nutrient recycling from e.g. wastewater and thereby contribute to environmental amelioration are struvite precipitation and ammonia stripping. By combining anaerobic digestion and nutrient recovery technologies on the digestate, a treatment process that provides both renewable energy and plant nutrients is achieved. This review will examine the effectiveness of ecotechnologies for the recovery and reuse of nitrogen and phosphorus from anaerobic digestate with the aim of reducing the impact of waste on the environment.
\end{abstract}

Methods: We will search for both academic and grey literature published after 2013. English language searches will be performed in 4 bibliographic databases, and Google Scholar, while searches in 41 specialist websites will be performed in English, Finnish, Polish and Swedish. Eligibility screening will be conducted at two levels: title and abstract and full text. Included eligible studies will be subject to a critical appraisal that will assess external and internal study validity. We will extract information on study characteristics, intervention, comparators, effect modifiers, and measured outcomes. Data synthesis will involve narrative synthesis of each included study of sufficient validity. Quantitative synthesis (i.e. meta-analysis) may be possible in cases where a sufficient number of studies report similar types of outcomes.

Keywords: Ammonium sulphate, Baltic Sea, Circular economy, Fertilisers, Manure, Nutrient reuse, Nutrient recycle, Soil enhancers, Struvite

*Correspondence: biljana.macura@sei.org; bmacura@gmail.com

1 Stockholm Environment Institute, Linnégatan 87D, Stockholm, Sweden

Full list of author information is available at the end of the article 


\section{Background}

Soil fertility and global food security depend on a regular addition of plant-available nutrients, such as nitrogen $(\mathrm{N})$ and phosphorus $(\mathrm{P})$, either in the form of manufactured fertilisers or animal manure, to agricultural soils [1]. There is a thin line between the optimum amount and timing of $\mathrm{N}$ fertiliser and its over-supply. $\mathrm{N}$ over-supply can quickly lead to serious environmental problems, since excess $\mathrm{N}$ is typically lost from the soil system, contaminating bodies of water $[2,3]$. In contrast to $\mathrm{N}$, which is effectively unlimited in its atmospheric form, high-quality rock reserves of $\mathrm{P}$ are limited and expected to deplete within a few hundred years [1]. P does not leach through the soil but it is prone to excessive soil accumulation, and is subsequently exposed to the risk of erosion into water courses while being sorbed to soil particles [4].

Environmental problems associated with $\mathrm{N}$ and $\mathrm{P}$ use are particularly pressing in the Baltic Sea Region (BSR), since excessive inputs of nutrients coming from the surrounding land are among the primary causes of the Baltic Sea eutrophication [5]. N and P entering water bodies that originate from the application of synthetic fertilisers or farmyard manure are regarded as non-point source pollution. As of 2014, non-point sources in the BSR contributed $46.5 \%$ and $35.7 \%$ of total $\mathrm{N}$ and $\mathrm{P}$ riverine loads, respectively [6]. Point source pollutants are another significant $\mathrm{N}$ and $\mathrm{P}$ loads to BSR, and mostly originate from wastewater treatment plants (WWTPs). The contribution of point source pollutants to total riverine load entering into the Baltic Sea in 2014 was considerably smaller than that of non-point sources, i.e. $11.7 \%$ and $23.5 \%$ for total $\mathrm{N}$ and P, respectively [6].

In agriculture, nutrient recovery and reuse practices have a potential to address the most pressing problems related to nutrients use in the food chain, such as pollution, depletion of finite resources (such as P), and waste management. Agricultural waste consists of livestock manure, primary agricultural residuals (such as post-harvest crop residuals), and secondary agricultural residuals (from crop processing in agricultural industries). If not properly managed, this waste can be a significant environmental and economic burden [7].

Spreading manure on agricultural land constitutes approximately $53 \%$ of the P and $33 \%$ of the $\mathrm{N}$ applied annually to agricultural soils in the EU27 [8]. However, the spatial segregation of crop-intensive and livestockintensive areas leads to uneven spatial distribution of manure, creating nutrient-deficient areas and nutrient hot-spots [9-11]. Finding cost-effective manure processing technologies to create safe and stable fertilisers from organic waste streams is thus a fundamental quest for sustainable agricultural production.
Domestic wastewater also represents an organic waste stream, from which nutrients can be recovered for agricultural use. The focus within the wastewater sector has, however, traditionally been on removal of organic matter, and $\mathrm{P}$ (including $\mathrm{N}$ to a certain degree) from the effluent by applying various treatment methods to protect receiving waters against eutrophication, rather than on nutrient recovery per se. Since recently, however, there is a shift in thinking towards circular economy that is defined as an economy where the value of products, materials and resources is maintained in the economy for as long as possible, and the generation of waste minimized [12]. This paradigm applied to the wastewater sector means a shift from the sole focus on waste treatment and nutrient removal to the recovery of energy and nutrients from waste and further reuse of these products [13,14].

Some nutrient reuse from domestic wastewater ( $P$ especially) is being done via application of sludge to agricultural fields. The $\mathrm{P}$ content in sludge depends on whether P removal processes are applied at the WWTP where $\mathrm{P}$ removal from wastewater into the sludge can be achieved by different chemical precipitation or biological removal processes [15]. The suitability of sludge as a fertiliser in agriculture is, however, debated in many countries due to contaminants that can be found in it. In addition, WWTPs are typically not located close to the arable land where sludge from wastewater processing could be applied [11]. Furthermore, the recovery of $\mathrm{N}$ through sludge application is low when compared to $\mathrm{P}$ recovery rate, since most $\mathrm{N}$ is either removed by denitrification or remains in the treated wastewater at conventional WWTPs [13]. For example, Van der Hoek et al. [16] showed that for Amsterdam's WWTP about $38 \%$ of the incoming $\mathrm{N}$ was captured in the sludge. Out of all N-carrying inflows to the WWTP, urine would be the most interesting source for $\mathrm{N}$ recovery if captured separately [16]. Thus, separate collection and treatment of blackwater (wastewater from the toilet only) captures this $\mathrm{N}$-rich stream and is a technical solution on the rise in several countries [17].

Nutrient recovery technologies can be applied to different waste streams, where a higher starting nutrient concentration will make the waste stream in question obviously more valuable. Anaerobic digestion of sludge, agricultural waste and blackwater is widely applied. Anaerobic digestion produces biogas which can be used as renewable energy. Dewatering of the digestate, often applied to reduce its weight, results in a liquid and a solid digestate phases. The liquid phase of anaerobic digestate is a concentrated source of nutrients, such as $\mathrm{N}$ and $\mathrm{P}$, to which then nutrient recovery technologies can be applied. By combining anaerobic digestion and nutrient recovery technologies, a treatment process can be 
achieved that provides both renewable energy and nutrients for plants. Van der Hoek et al. [16] showed that the digestate has a potential of recovering $27 \%$ of the incoming $\mathrm{N}$ to the WWTP. Nutrient recovery from wastewater and agricultural wastes could decrease the need for mineral $\mathrm{N}$ and $\mathrm{P}$ fertilisers, reducing the pressure on respective biogeochemical cycles $[18,19]$ and further is an important and integral contribution of the wastewater sector to a circular economy.

\section{Potential solutions}

Two promising technologies for $\mathrm{N}$ and $\mathrm{P}$ recovery identified in systematic maps of ecotechnologies for recovering nutrients and carbon from domestic wastewater [20] and agricultural waste streams [21] are struvite precipitation and ammonia stripping.

Struvite precipitation and recovery is an ecotechnology that can be used mainly for $P$ recovery and was one of the most represented ecotechnologies identified in both systematic maps (unpublished data). Struvite is a crystalline mineral composed of equimolar concentrations of magnesium, ammonium and phosphate with the chemical formula $\mathrm{MgNH}_{4} \mathrm{PO}_{4}{ }^{*} 6 \mathrm{H}_{2} \mathrm{O}$. Struvite is formed under alkaline conditions and the process depends on specific and controlled molar ratios in the liquid, $\mathrm{pH}$, aeration, reaction time and temperature. Usually, magnesium must be added in order to achieve sufficient struvite precipitation when the technique is applied to domestic or manure wastewater. Under optimal conditions, up to $94 \%$ of the P can be recovered as struvite and approximately half as much $\mathrm{N}$, because struvite contains approximately $0.5 \mathrm{~kg}$ of N per $\mathrm{kg}$ of $\mathrm{P}$ [22]. Struvite is an effective, slow-release fertiliser with a relatively low content of contaminants, which can replace fertilisers produced from phosphate rock [22]. The value of struvite as fertiliser has only been recently understood and it is now the focus of increasing research attention [23].

Ammonia stripping is applied to liquids containing high concentrations of ammonia [24,25], and using this method up to $98 \%$ of the ammonia in the liquid can be removed in a given flow stream [25]. High temperature and $\mathrm{pH}$ increase efficiency of ammonia stripping since this leads to a larger fraction of $\mathrm{N}$ as gaseous ammonia. The stripped ammonia gas is then recovered by absorption to an acid, commonly sulphuric acid. The resulting product is a low $\mathrm{pH}$ ammonium sulphate, used as a fertiliser recommended for use on soils with alkaline or neutral reaction [24].

Both struvite precipitation and ammonia stripping could potentially be incorporated into existing WWTPs and manure management processes to enhance nutrient recovery, improve WWTP function, and contribute to an increased P recovery. The liquid phase of anaerobic digestate is a concentrated stream of nutrients, commonly produced in the current management process of both manure and wastewater. Therefore, the focus of this review is on the liquid phase of anaerobic digestate as a source of nutrients for recovery. We have chosen struvite recovery and ammonia stripping for this review in order to focus on both $\mathrm{P}$ and $\mathrm{N}$ recovery, since the $\mathrm{N}$ content of struvite is too low to be considered as a $\mathrm{N}$ fertiliser.

Although there are some relevant reviews on the topic $[9,26,27]$, to our knowledge, no systematic reviews of effectiveness of modern ecotechnologies for reuse of $\mathrm{N}$ and $\mathrm{P}$ from anaerobic digestate have been conducted. Here, we define ecotechnologies as "human interventions in social-ecological systems in the form of practices and/ or biological, physical, and chemical processes designed to minimise harm to the environment and provide services of value to society" [28]. This definition was produced by a thematic synthesis of definitions in the literature, encompassing both hard (e.g. mechanical or chemical) and soft (e.g. behaviours and practices) technologies and has been used in two other, preceding systematic maps [20,21].

\section{Stakeholder engagement}

The topic for this review was initially proposed by the research funder BONUS (https://www.bonusportal.org/). The scope of the project was then refined through expert discussions as part of the process of drafting an application in response to the call by the research funder. The scope and the search strategy were further refined by a stakeholder group consisting of the broader BONUS RETURN project consortium members (see https://www. bonusreturn.com/), local stakeholders from the three BONUS RETURN case study areas in Finland, Poland and Sweden, as well as external experts from these countries, which explains the Baltic Sea basin focus.

\section{Objective of the review}

The primary question for this systematic review is:

Are struvite precipitation and ammonia stripping effective ecotechnologies for recovery and reuse of nitrogen and phosphorus from anaerobic digestate?

The secondary questions are as follows:

SQ1: How effective are struvite precipitation and ammonia stripping for the recovery of nitrogen and phosphorus from anaerobic digestate?

SQ2: How effective are recovered products from these processes (struvite and ammonium sulphate) as fertilisers?

This review will focus on struvite precipitation and ammonia stripping currently developed and applied globally. We will investigate application of recovered products (struvite and ammonium sulphate) in the Baltic 
Sea and boreo-temperate regions. Figure 1 describes the study system and the relation between review questions.

The first secondary question (SQ1) has the following components:

Population(s) Agricultural residuals and domestic wastewater (including blackwater) globally.

Intervention(s) Struvite precipitation and ammonia stripping undertaken for the purposes of recovering $\mathrm{N}$ and $\mathrm{P}$ from the liquid phase anaerobic digestate.

Comparator(s) Before ecotechnology use, a control site without an ecotechnology, a comparison between different ecotechnologies, different intensities of the same ecotechnology, time series after ecotechnology implementation.

Outcome(s) Recovery potential of $\mathrm{N}$ compounds (total $\mathrm{N}$, ammonium and/or ammonia) and $\mathrm{P}$ compounds [total P, phosphate)] expressed as a recovered percentage in the digestate flow stream and/or total recovery in the wastewater.

The second secondary question (SQ2) has the following components:
Population(s) Ecosystems of boreo-temperate regions, with a focus on the Baltic Sea region (as requested by stakeholders).

Intervention(s) Struvite and ammonium sulphate used as fertilisers.

Comparator(s) Before the product use, a control site without a product, a comparison between different products, different intensities of the same product, time series after product implementation.

Outcome(s) Crop yield, N and P uptake by plants and their use efficiency, dissolution rate, apparent $\mathrm{P}$ recovery, apparent $\mathrm{N}$ recovery, related fertiliser efffciency, fertiliser use efficiency (including $\mathrm{N}$ and $\mathrm{P}$ use efficiency), and similar.

\section{Methods}

The review follows the Collaboration for Environmental Evidence Guidelines and Standards for Evidence Synthesis in Environmental Management [29] and this protocol conforms to ROSES reporting standards (as will the final review) [30] (see Additional file 1).

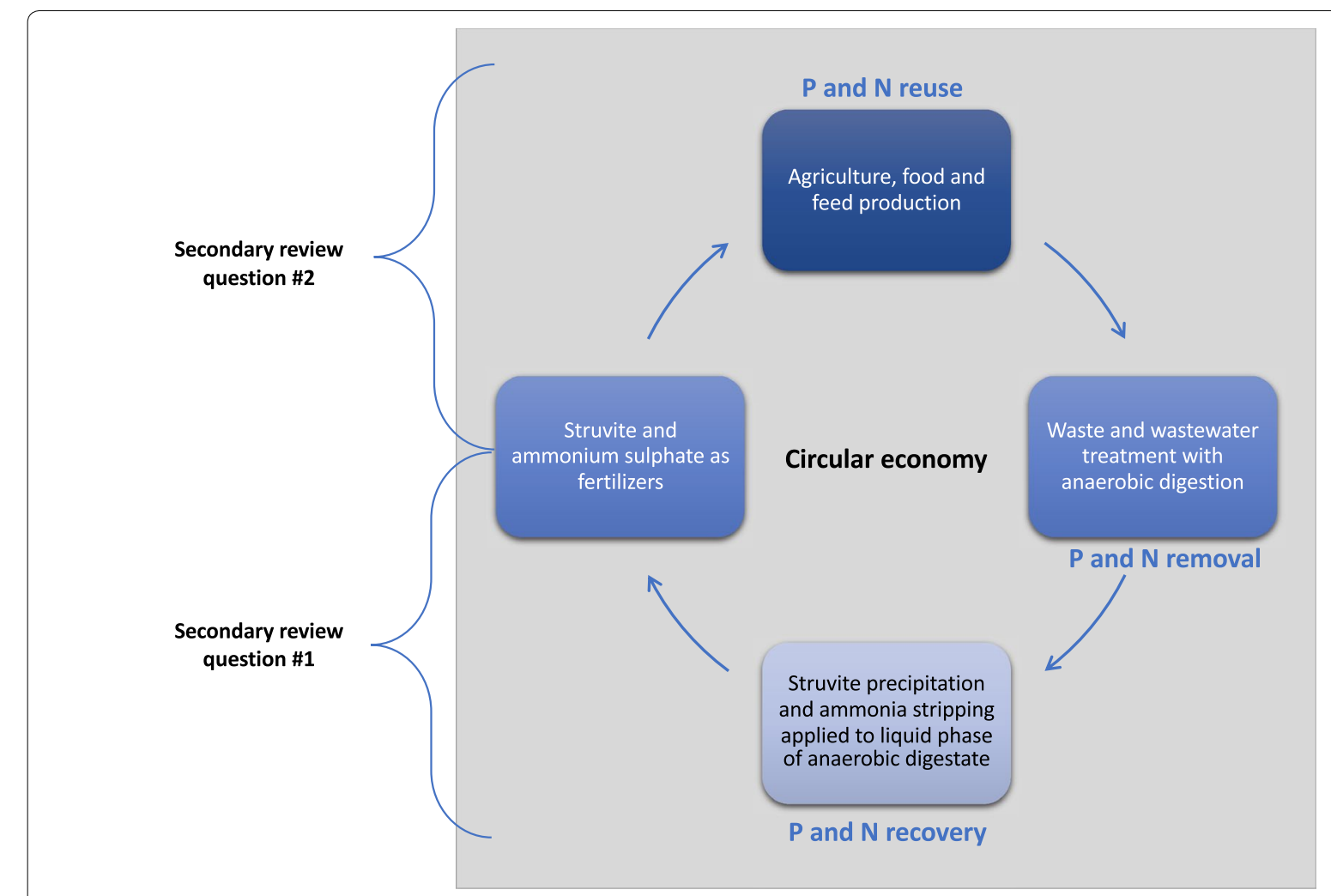

Fig. 1 Conceptual diagram with review context and questions. The diagram is simplified, and it is showing an ideal system. There are P and N losses along the cycle 


\section{Searching for articles}

\section{Selection of studies identified in the systematic maps}

We will hand search the databases of two ongoing systematic maps relating to ecotechnologies for recovery of carbon, N and P from domestic wastewater [20] and waste streams from agriculture [21]. These systematic maps are based on searches performed in: (1) Scopus, Web of Science Core Collections, Electronic Theses Online Service, Digital Access to Research Theses and Directory of Open Access Journals using English search terms; and, (2) Google Scholar and (3) 38 organisational websites using English, Finnish, Polish and Swedish search terms. Searches were performed between May 2017 and August 2018, and results were restricted to publication dates between 2013 and 2017.

\section{Search update and amendment}

In order to find the most recent and relevant literature, we will perform additional searches as described below. We are interested in recently published literature in line with the paradigm shift towards circular economy and so will restrict our searches to the period after 2013 .

\section{Bibliographic databases}

We will search for evidence in following databases:

1. Scopus

2. Web of Science (WoS) Core Collections (consisting of the following indexes: SCI-EXPANDED, SSCI, A\&HCI, CPCI-S, CPCI-SSH, and ESCI)

3. Electronic Theses Online Service (eThOS)

4. Digital Access to Research Theses (DART)

5. Directory of Open Access Journals (DOAJ)

Searches will be performed using subscriptions of Warsaw University of Life Sciences and Stockholm University. These searches will be conducted using English language search terms.

The following search strings will be used in bibliographic databases:

Search string for SQ1:

(struvite OR " $\mathrm{MgNH}_{4} \mathrm{PO}_{4}$ " OR " $\mathrm{NH}_{4} \mathrm{MgPO}_{4}$ " OR "Magnesium ammonium phosphate" ${ }^{*}$ OR "Crystal green" OR (ammonium AND (sulphate* OR sulfate* OR nitrate* $\left.^{*}\right)$ OR mascagnite* OR ((stripp* OR scrub*) AND (ammoni* OR NH3 OR nitrogen OR air OR steam))) AND (digest* OR centrate* OR supernatant* OR dewater* OR "solid-liquid" OR "bio refiner" OR "reject water" OR effluent* OR "liquid phase") [shown as formatted for WoS]

Search string for SQ2:

(struvite OR " $\mathrm{MgNH}_{4} \mathrm{PO}_{4}$ " OR " $\mathrm{NH}_{4} \mathrm{MgPO}_{4}$ " OR "Magnesium ammonium phosphate*" OR "Crystal green"
OR mascagnite OR (ammoni* AND (sulphate*" OR sulfate*"))) AND (fertili* OR field* OR farm* OR soil* OR agricult* OR arable OR agron* OR nutrient* OR crop* OR seed* OR food* OR yield* OR produc* OR uptake OR plant* OR vegetat* OR absor*) [shown as formatted for WoS]

\section{Search engines}

Searches will also be performed in Google Scholar, which is an effective tool for identifying grey literature [31]. The searches for SQ1 will make use of terms related both to ecotechnologies (e.g. 'struvite precipitation'; 'ammonia stripping'), and outcome terms (e.g. 'nitrogen recycling, 'phosphorus', ammonium sulphate). The searches for SQ2 will make use of terms related to struvite and ammonium sulphate and combinations of outcome terms (e.g. 'soil quality, 'crop yield'). Searches will be performed in English, Swedish, Finnish and Polish. Google Scholar searches will be restricted to articles published after 2013, as above. The first 1000 search results will be extracted as citations using Publish or Perish software [32] and introduced into the duplication removal and screening workflow alongside records from bibliographic databases. See Additional file 2 for details of WoS, Scopus and Google Scholar searches.

\section{Organisational websites}

Searches will be performed across a suite of relevant organisational websites (see Table 1). These searches will be particularly important for capturing grey literature. Each website will also be hand-searched for relevant publications. These searches will also use terms related both to synonyms for ecotechnologies and combinations of outcome terms and reuse terms. Searches will be performed in English, Swedish, Finnish and Polish corresponding to the case-study countries within the BONUS RETURN project as well as many of the Baltic languages. See Table 1 for a list of specialist websites and Additional file 2 for example search terms in English and Swedish. Literature from organisational websites will be screened separately before being combined with other records.

\section{Supplementary searches}

We will search for eligible literature in the bibliographies of reviews identified during the review process (see a draft list of relevant reviews in Additional file 2).

\section{Testing comprehensiveness of the search}

Two lists of articles of known relevance to the review were screened against search results to examine whether the search strategies are able to locate relevant evidence (see lists of benchmark studies in Additional file 2). If 
Table 1 A list of specialist websites and search languages

\begin{tabular}{|c|c|c|}
\hline$\overline{\#}$ & Website & Search language \\
\hline 1 & Foundation for Applied Water Research (STOWA) (http://www.stowa.nl) & English \\
\hline 2 & Ekologgruppen i Landskrona AB (http://www.ekologgruppen.com/) & English \\
\hline 3 & Danish Centre for Environment and Energy (DCE) (http://dce.au.dk) & English \\
\hline 4 & European Environment Agency (EEA) (https://www.eea.europa.eu/) & English \\
\hline 5 & Finnish Environment Institute (SYKE) (http://www.syke.fi) & English \\
\hline 6 & Federal Environment Agency (UmweltBundesAmt, Germany) (https://www.umweltbundesamt.de) & English \\
\hline 7 & Leibniz Institute of Freshwater Ecology and Inland Fisheries (IGB) (http://www.igb-berlin.de) & English \\
\hline 8 & EAWAG Aquatic Research (https://www.eawag.ch/en/) & English \\
\hline 9 & Netherlands National Institute for Public Health and the Environment (RIVM) (https://www.rivm.nl/en) & English \\
\hline 10 & United States Environmental Protection Agency (US EPA) (https://www.epa.gov/) & English \\
\hline 11 & European sustainable phosphorus platform (https://phosphorusplatform.eu/) & English \\
\hline 12 & $\begin{array}{l}\text { Organic Farm Knowledge platform } \\
\text { (https://organic-farmknowledge.org/search-toolbox) }\end{array}$ & English \\
\hline 13 & Sustainable Sanitation Alliance (www.susana.org) & English \\
\hline 14 & Swedish Environmental Protection Agency (SEPA) (http://www.naturvardsverket.se) & English, Swedish \\
\hline 15 & Swedish Board of Agriculture (http://www.jordbruksverket.se) & English, Swedish \\
\hline 16 & The Swedish Agency for Marine and Water Management (https://www.havochvatten.se) & English, Swedish \\
\hline 17 & Swedish directory of Master thesis (DiVA) (http://www.diva-portal.org) & English, Swedish \\
\hline 18 & The Swedish Water \& Wastewater Association (SWWA) (http://www.svensktvatten.se) & Swedish \\
\hline 19 & Federation of Swedish Farmers (http://www.Irf.se) & Swedish \\
\hline 20 & The Swedish Environmental Institute (http://www.IVL.se) & Swedish \\
\hline 21 & Agro base (http://agro.icm.edu.pl/agro) & Polish \\
\hline 22 & Tech Base (http://baztech.icm.edu.pl) & Polish \\
\hline 23 & Catalogue of the WULS diploma and doctoral dissertations (https://sgw0.bg.sggw.pl) & Polish \\
\hline 24 & Archive of Diploma Theses of the University of Agriculture Hugo Kołłątaj, Krakow (https://apd.ur.krakow.pl/catalogue) & Polish \\
\hline 25 & Archive of Diploma Papers of the University of Technology and Life Sciences in Bydgoszcz (https://apd.utp.edu.pl/catalogue) & Polish \\
\hline 26 & Central Catalog of Polish Journals (http://mak.bn.org.pl/cgi-bin/makwww.exe?BM=7) & Polish \\
\hline 27 & NUKat (http://katalog.nukat.edu.pl) & Polish \\
\hline 28 & Portal of Scientific Journals (http://www.ejournals.eu) & Polish \\
\hline 29 & Journal repository of the Nicolaus Copernicus University (http://wydawnictwoumk.pl/czasopisma) & Polish \\
\hline 30 & Repository of the Open Science Center (http://depot.ceon.pl) & Polish \\
\hline 31 & SYMPOnet (https://gate.bg.pw.edu.pl/) & Polish \\
\hline 32 & Melinda (https://melinda.kansalliskirjasto.fi) & Finnish \\
\hline 33 & ARTO (https://arto.linneanet.fi/vwebv/searchBasic?sk=fi_FI) & Finnish \\
\hline 34 & HELDA Institutional repository (https://helda.helsinki.fi) & Finnish \\
\hline 35 & DORIA Institutional repository (https://www.doria.fi) & Finnish \\
\hline 36 & JUKURI (http://jukuri.luke.fi) & Finnish \\
\hline 37 & TAMPUB (http://tampub.uta.fi) & Finnish \\
\hline 38 & THESEUS (http://www.theseus.fi) & Finnish \\
\hline 39 & University of Lapland (http://lauda.ulapland.fi) & Finnish \\
\hline 40 & Aalto University (https://aaltodoc.aalto.fi) & Finnish \\
\hline 41 & SYKE library collection (http://kirjasto.ymparisto.fi/syke/fi/search_yha.htm) & Finnish \\
\hline
\end{tabular}

articles were not found during the scoping exercise, search terms were examined to identify the reasons why articles were missed, and search terms were modified accordingly.

\section{Assembling library of search results}

Results of the searches in bibliographic databases and Google Scholar will be combined, and duplicates removed prior to screening. A library of search results will be assembled in a review management software (i.e. EPPI reviewer [33]). 


\section{Article screening and study eligibility criteria Screening process}

Screening will be conducted at two levels: at title and abstract level (conducted together for efficiency), and at full text level. The full texts will be retrieved, tracking those that cannot be located or accessed and reporting this in the final review report. Retrieved records will then be screened at full text.

Prior to commencing screening, consistency checking will be performed on a subset of articles (10\%) at both title and abstract level and full text level screening. A subset of title and abstract records and full texts will be independently screened by three reviewers. The results of the consistency checking will then be compared between reviewers and all disagreements will be discussed in detail. Where the level of agreement is low (below c. $80 \%$ agreement), further consistency checking will be performed on an additional set of articles and then discussed. Following consistency checking (i.e. when agreement is above $80 \%$ ), records will be screened by one experienced reviewer (and EPPI reviewer's machine learning component will be used on a same set of records to avoid errors in screening).

\section{Eligibility criteria}

The following criteria will be applied at all levels of screening:

For SQ1:

Eligible population(s) Liquid phase of anaerobic digestate from agricultural residuals and domestic wastewater (including blackwater). Studies conducted anywhere across the globe will be eligible.

Eligible intervention(s) Struvite precipitation and ammonia stripping undertaken for the purposes of recovering $\mathrm{N}$ and $\mathrm{P}$.

Eligible comparator(s) Before ecotechnology use, a control site without an ecotechnology, a comparison between different ecotechnologies, different intensities of the same ecotechnology, time series after ecotechnology implementation.

Eligible outcome(s) Recovery potential of $\mathrm{N}$ compounds (total $\mathrm{N}$, ammonium and/or ammonia) and $\mathrm{P}$ compounds (total $\mathrm{P}$, phosphate) expressed as recovered percentage in the digestate flow stream and/or total recovery in the wastewater

Eligible languages English, Finnish, Polish and Swedish
For SQ2:

Eligible population(s) Ecosystems of boreo-temperate regions, with a focus on the Baltic Sea region. Eligible studies will be located in both hemispheres, with fully humid temperate $(\mathrm{Cfa}, \mathrm{Cfb}, \mathrm{Cfc})$ and fully humid boreal (Dfa, Dfb, Dfc, Dfd) climates according to the Köppen-Geiger climate classification [34]. Eligible interventions(s) Struvite and ammonium sulphate recovered from anaerobic digestate and used as fertilisers.

Eligible comparator(s) None, before the product use, a control site without a product, a comparison between different products, different intensities of the same product, time series after product implementation.

Eligible outcome(s) Effectiveness of the products expressed as crop yields, $\mathrm{N}$ and $\mathrm{P}$ release and uptake by plants, soil quality, apparent $\mathrm{P}$ recovery, apparent $\mathrm{N}$ recovery, related fertiliser efficiency, fertiliser use efficiency (including $\mathrm{N}$ and $\mathrm{P}$ use efficiency).

Eligible languages English, Finnish, Polish and Swedish.

We will provide a list of articles excluded at title and abstract level, and at full text level. The list will include reasons for exclusion.

\section{Study validity assessment}

Eligible studies will be subject to a study validity assessment. The assessment will evaluate external and internal study validity and categorise relevant studies as having a high, medium or low validity. This information will be used into separate studies during narrative synthesis and in sensitivity analyses during the quantitative synthesis stage (if performed). Studies with unacceptably low validity may be excluded from the review. The detailed criteria for the study validity assessment of included studies (i.e. critical appraisal tool) will be developed during the review process in a 1-day workshop with experts on the review team and external subject experts. The critical appraisal tool will be tested on a set of 5 studies by the entire team. The study validity assessment may consider several elements, including:

1. Level of methodological details reported (which affects the ability to judge the validity);

2. Study design (e.g. BA/CI/BACI);

3. Number of replicates and scale of replication

4. Confounding factors and susceptibility to bias.

Study validity criteria will be tailored to and conducted for studies in each review question separately. The decision during the study validity assessment will be recorded 
in a detailed and transparent manner. The validity of a study will be assessed by one reviewer and checked by a second reviewer. Final decisions regarding doubtful cases will be taken by the review team as a whole. A list of studies excluded based on quality assessment will be provided in an appendix together with the reasons for exclusion.

\section{Data coding and extraction strategy}

Data will be extracted from included studies and recorded in spreadsheets that include pre-determined coding adapted for each secondary question. A draft version of data extraction sheet is in Additional file 3. We will extract information on study characteristics, intervention details, comparators, effect modifiers, study validity assessment scores and study findings. This list may be expanded during the review process depending on the type and variety of included studies. The outcome means and measures of variation (standard deviation, standard error, or confidence intervals) will be extracted from tables and graphs (using image analysis software if needed). In case of unobtainable data from published materials, the review team will ask authors of relevant articles for access to unpublished raw data. The review team will calculate summary statistics if the raw data are provided. All extracted data records will be made available as additional files. A consistency checking exercise will be done before coding and data extraction on a subset (10\%) of records by all reviewers. All disagreements will be discussed, and the coding scheme will be clarified where needed.

\section{Potential effect modifiers/reasons for heterogeneity}

The following factors, which potentially can cause variation in measured outcomes, will be considered and recorded if reported in primary studies or available from authors:

\section{For SQ1:}

- Specific characteristics of intervention and ecotechnology process parameters including: temperature, reactor type, amount of chemicals added, NH4:P molar ratios

- Type of a substrate used for anaerobic digestion

- Type of waste treatment processes before anaerobic digestion phase and before application of struvite recovery or ammonia stripping

- Study design, including study scale and sampling method.

For SQ2:

- Climatic conditions

- Physical and chemical conditions of soil
- Type of product used as fertiliser: granular, liquid, etc.

- Amount of applied fertiliser, purity of fertiliser or level of organic pollutants

- Plant species exposed to the fertilisers

- Study design, including study scale and sampling method.

More effect modifiers and reasons for heterogeneity may be recorded and extracted from the studies during the review process.

\section{Data synthesis and presentation}

A narrative synthesis will describe the validity of the results along with summary of findings (in a graphical and tabular form) of each included study. We will produce a database of studies including full meta-data that can be visualised in an evidence atlas. Meta-analysis may be used to synthesise quantitative data and it will be possible in cases where a sufficient number of studies (for our purposes, we will set a lower limit of 3) report similar types of outcomes. In such cases, effect sizes will be standardised (as Hedges g) and weighted appropriately. Meta-regression and subgroup analysis of different study categories may be performed where sufficient data exist. We will also analyse the potential presence of publication bias. We will conduct sensitivity analysis based on critical appraisal judgement where sufficient studies allow (i.e. where 3 or more high validity studies remain). The review will also highlight and discuss methodological deficiencies of the relevant studies, and major knowledge gaps in the evidence base for each secondary question. Knowledge gaps will be highlighted by identifying un- or underrepresented subtopics using heat maps.

\section{Additional files}

Additional file 1. ROSES form for systematic review protocols.

Additional file 2. Scoping exercise.

Additional file 3. Data extraction sheet.

\section{Acknowledgements}

We thank the BONUS Secretariat for their generous funding. We are grateful to Robin Harder for providing valuable comments on the previous version of the manuscript

\section{Authors' contributions}

BM drafted the first version of the manuscript. SLJ and MP, together with EK wrote the background of the manuscript. All authors read and approved the final manuscript.

\section{Funding}

This review will be conducted as part of BONUS RETURN project. BONUS RETURN project is supported by BONUS (Art 185), funded jointly by the EU and Swedish Foundation for Strategic Environmental Research FORMAS, 
Sweden's innovation agency VINNOVA, Academy of Finland and National Centre for Research and Development in Poland.

\section{Availability of data and materials}

Not applicable.

\section{Ethics approval and consent to participate}

Not applicable.

\section{Consent for publication}

Not applicable.

\section{Competing interests}

The authors declare that they have no competing interests.

\section{Author details}

1 Stockholm Environment Institute, Linnégatan 87D, Stockholm, Sweden

${ }^{2}$ Research Institutes of Sweden, Ultunaallén 4, Uppsala, Sweden. ${ }^{3}$ Department of Hydraulic Engineering, Warsaw University of Life Sciences, Nowoursynowska 166, 02-787 Warsaw, Poland. ${ }^{4}$ Africa Centre for Evidence, University of Johannesburg, Johannesburg, South Africa. ${ }^{5}$ Research Institutes of Sweden, Drottning Kristinas väg 61, Stockholm, Sweden.

Received: 4 June 2019 Accepted: 12 July 2019

Published online: 02 August 2019

\section{References}

1. Dawson CJ, Hilton J. Fertiliser availability in a resource-limited world: production and recycling of nitrogen and phosphorus. Food Policy. 2011;36:S14-22

2. Carpenter SR, Caraco NF, Correll DL, Howarth RW, Sharpley AN, Smith VH. Nonpoint pollution of surface waters with phosphorus and nitrogen. Ecol Appl. 1998;8:559-68.

3. Stark CH, Richards KG. The continuing challenge of nitrogen loss to the environment: environmental consequences and mitigation strategies. Dyn Soil Dyn Plant. 2008;2:41-55.

4. Bennett EM, Carpenter SR, Caraco NF. Human impact on erodable phosphorus and eutrophication: a global perspective: increasing accumulation of phosphorus in soil threatens rivers, lakes, and coastal oceans with eutrophication. Bioscience. 2001:51:227-34.

5. Ylöstalo P, Seppälä J, Kaitala S, Maunula P, Simis S. Loadings of dissolved organic matter and nutrients from the Neva River into the Gulf of Finlandbiogeochemical composition and spatial distribution within the salinity gradient. Mar Chem. 2016:186:58-71.

6. HELCOM. Sources and pathways of nutrients to the Baltic Sea. In: Baltic Sea environment proceedings, no 153. 2018.

7. Gontard N, Sonesson U, Birkved M, Majone M, Bolzonella D, Celli A, Angellier-Coussy H, Jang G-W, Verniquet A, Broeze J, et al. A research challenge vision regarding management of agricultural waste in a circular bio-based economy. Crit Rev Environ Sci Technol. 2018;48(6):614-54

8. van Dijk KC, Lesschen JP, Oenema O. Phosphorus flows and balances of the European Union Member States. Sci Total Environ. 2016;542:1078-93.

9. Buckwell A, Nadeu E. Nutrient Recovery and Reuse (NRR) in European agriculture: a review of the issues, opportunities, and actions. Brussels: RISE Foundation; 2016

10. Shober AL, Maguire RO. Manure management. In: Shober AL, editor. Reference module in earth systems and environmental sciences. New York: Elsevier; 2018.

11. Jones DL, Cross P, Withers PJA, DeLuca TH, Robinson DA, Quilliam RS, Harris IM, Chadwick DR, Edwards-Jones G. REVIEW: nutrient stripping: the global disparity between food security and soil nutrient stocks. J Appl Ecol. 2013;50(4):851-62.

12. European Commission. Communication from the Commission to the European parliament, the Council, the European Economic and Social committee and the Committee of the Regions: Closing the loop-an EU action plan for the Circular Economy. In: Commission E, ed. Document 52015DC0614, vol. COM(2015) 614 final. Brussels; 2015

13. Peccia J, Westerhoff P. We should expect more out of our sewage sludge Environ Sci Technol. 2015:49:8271-6.
14. Guest JS, Skerlos SJ, Barnard JL, Beck MB, Daigger GT, Hilger H, Jackson SJ, Karvazy K, Kelly L, Macpherson L, et al. A new planning and design paradigm to achieve sustainable resource recovery from wastewater. Environ Sci Technol. 2009;43(16):6126-30.

15. Yeoman S, Stephenson T, Lester J, Perry R. The removal of phosphorus during wastewater treatment: a review. Environ Pollut. 1988;49:183-233.

16. Van der Hoek $P$, Duijff $R$, Reinstra $O$. Nitrogen recovery from wastewater: possibilities, competition with other resources, and adaptation pathways. Sustainability. 2018;10:4605.

17. Skambraks AK, Kjerstadius H, Meier M, Davidsson Å, Wuttke M, Giese T. Source separation sewage systems as a trend in urban wastewater management: drivers for the implementation of pilot areas in Northern Europe. Sustain Cities Soc. 2017;28:287-96.

18. Rockström J, Steffen W, Noone K, Persson Å, Chapin lii FS, Lambin EF, Lenton TM, Scheffer M, Folke C, Schellnhuber HJ, et al. A safe operating space for humanity. Nature. 2009:461:472.

19. Steffen W, Richardson K, Rockström J, Cornell SE, Fetzer I, Bennett EM, Biggs $R$, Carpenter SR, de Vries W, de Wit CA, et al. Planetary boundaries: guiding human development on a changing planet. Science. 2015:347(6223):1259855.

20. Haddaway NR, Johannesdottir SL, Piniewski M, Macura B. What ecotechnologies exist for recycling carbon and nutrients from domestic wastewater? A systematic map protocol. Environ Evid. 2019;8:1.

21. Haddaway NR, Piniewski M, Macura B. What evidence exists relating to effectiveness of ecotechnologies in agriculture for the recovery and reuse of carbon and nutrients in the Baltic and boreo-temperate regions? A systematic map protocol. Environ Evid. 2019:8:5.

22. Rahman MM, Salleh MAM, Rashid U, Ahsan A, Hossain MM, Ra CS. Production of slow release crystal fertilizer from wastewaters through struvite crystallization - a review. Arabian J Chem. 2014;7(1):139-55.

23. Muhmood A, Lu J, Dong R, Wu S. Formation of struvite from agricultural wastewaters and its reuse on farmlands: status and hindrances to closing the nutrient loop. J Environ Manage. 2019;230:1-13.

24. Kinidi L, Tan IAW, Abdul Wahab NB, Tamrin KFB, Hipolito CN, Salleh SF. Recent development in ammonia stripping process for industrial wastewater treatment. Int J Chem Eng. 2018;2018:14.

25. Carey DE, Yang Y, McNamara PJ, Mayer BK. Recovery of agricultural nutrients from biorefineries. Bioresourc Technol. 2016;215:186-98.

26. Ma J, Kennedy N, Yorgey G, Frear C. Review of emerging nutrient recovery technologies for farm-based anaerobic digesters and other renewable energy systems. Washington: Washington State University; 2013.

27. Venkiteshwaran K, McNamara PJ, Mayer BK. Meta-analysis of non-reactive phosphorus in water, wastewater, and sludge, and strategies to convert it for enhanced phosphorus removal and recovery. Sci Total Environ. 2018;644:661-74.

28. Haddaway N, McConville J, Piniewski M. How is the term 'ecotechnology' used in the research literature? A systematic review with thematic synthesis. Ecohydrol Hydrobiol. 2018;18:247-61.

29. Collaboration for Environmental Evidence. Guidelines and standards for evidence synthesis in environmental management. Version 5.0. In. Pullin A, Frampton G, Livoreil B, Petrokofsky G, editors; 2018

30. Haddaway NR, Macura B, Whaley P, Pullin AS. ROSES RepOrting standards for systematic evidence syntheses: pro forma, flow-diagram and descriptive summary of the plan and conduct of environmental systematic reviews and systematic maps. Environ Evid. 2018;7(1):7.

31. Haddaway N, Collins A, Coughlin D, Kirk S. The role of Google Scholar in evidence reviews and its applicability to grey literature searching. PLOS ONE. 2015;10:e0138237

32. Harzing AW. Publish or Perish. https://harzing.com/resources/publish-orperish. 2007.

33. Thomas J, Brunton J, Graziosi S. EPPI-Reviewer 4.0: software for research synthesis. EPPI-Centre Software, 4.0 edn. London: Social Science Research Unit, Institute of Education, University of London; 2010.

34. Kottek M, Grieser J, Beck C, Rudolf B, Rubel F. World Map of the Köppen-Geiger climate classification updated. Meteorol Z. 2006;15:259-63.

\section{Publisher's Note}

Springer Nature remains neutral with regard to jurisdictional claims in published maps and institutional affiliations. 